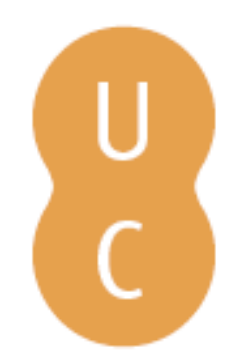

\title{
pommalina
}

\section{Anomia y dike en la Antígona de Sófocles y en Antígona frente a los jueces de} Andrés Pociña

\author{
Autor(es): $\quad$ Cendán Teijeiro, Noelia \\ Publicado por: Imprensa da Universidade de Coimbra; Annablume \\ URL \\ persistente: URI:http://hdl.handle.net/10316.2/40918 \\ DOI: $\quad$ DOI:https://doi.org/10.14195/978-989-26-1298-0_12 \\ Accessed : $\quad$ 26-Apr-2023 14:13:33
}

A navegação consulta e descarregamento dos títulos inseridos nas Bibliotecas Digitais UC Digitalis, UC Pombalina e UC Impactum, pressupõem a aceitação plena e sem reservas dos Termos e Condições de Uso destas Bibliotecas Digitais, disponíveis em https://digitalis.uc.pt/pt-pt/termos.

Conforme exposto nos referidos Termos e Condições de Uso, o descarregamento de títulos de acesso restrito requer uma licença válida de autorização devendo o utilizador aceder ao(s) documento(s) a partir de um endereço de IP da instituição detentora da supramencionada licença.

Ao utilizador é apenas permitido o descarregamento para uso pessoal, pelo que o emprego do(s) título(s) descarregado(s) para outro fim, designadamente comercial, carece de autorização do respetivo autor ou editor da obra.

Na medida em que todas as obras da UC Digitalis se encontram protegidas pelo Código do Direito de Autor e Direitos Conexos e demais legislação aplicável, toda a cópia, parcial ou total, deste documento, nos casos em que é legalmente admitida, deverá conter ou fazer-se acompanhar por este aviso.

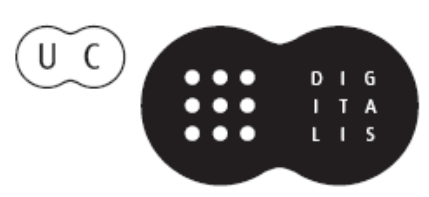




\section{O Livro do Tempo: \\ Escritas e reescritas}

\section{Teatro Greco-Latino e sua recepção II}

Maria de Fátima Silva, Maria do Céu

Fialho \& José Luís Brandão (coords.)

IMPRENSA DA UNIVERSIDADE DE COIMBRA 


\title{
ANOMIA y DIKE EN LA $A N T I ́ G O N A$ de Sófocles y en $A N T I ́ G O N A$ Frente a los JuECES de Andrés Pociña (Anomia and dike in Sophocles' Antigone and Andrés Pociña' Antigone in front of the judges)
}

\author{
Noelia Cendán Teijeiro (noelia.cendan@usc.es) \\ Universidad de Santiago de Compostela
}

\begin{abstract}
Resumen - Este trabajo analiza las conexiones existentes entre la tragedia clásica Antígona, de Sófocles, y la reescritura contemporánea realizada por Andrés Pociña, Antigona frente a los jueces. En atención a dilucidar los aspectos que fundamentan el vínculo entre ambas obras, se pone especial atención al estudio de los términos anomia $y$ dike. La importancia de estos dentro de la moral cultural griega revela aspectos que determinan buena parte del proceso de reescritura.
\end{abstract}

Palabras clave - Antígona, Sófocles, Andrés Pociña, dike, anomia.

Aвstract - This study analyzes the literary relations between the classical tragedy Antigone of Sophocles and Antigone in front of the judges of Andrés Pociña. In particular, the aim of this work is to understand the working of the concepts dike and anomia. The importance of these concepts in the Greek moral shows their literay dimension in the new text of Andrés Pociña.

Keywords - Antigone, Sophocles, Andrés Pociña, dike, anomia.

\section{La Antígona de Sófocles y la Antígona frente a los Jueces de An- DRÉs Pociña. La REESCRITURA COMO FUENTE de TRANSFORMACIÓN}

Las relaciones textuales, entendidas en sentido amplio (intra y extratextual) que una obra establece con aquella que ejerce de alma mater resultan elementos de valor incalculable para el estudio del proceso de reescritura. En este caso, Antígona frente a los jueces, de Andrés Pociña, debe ser analizada a la luz de la sempiterna Antígona de Sófocles, tragedia que ha sido objeto de adaptación y reescritura a lo largo de la historia literaria de occidente ${ }^{1}$. Pese a la dificultad que entraña, al realizar este tipo de estudios, determinar con precisión la relación literaria y textual que vincula ambas obras, fundamentalmente desde un punto de

${ }^{1}$ La historia de las reescrituras de la tragedia Antígona resulta profusa en detalles, si bien no forma parte del objetivo propuesto en este trabajo profundizar en ella. Para una mayor información en este tema vide Pociña y López 2010: 345-370, en cuyo artículo realizan matizaciones a la amplia obra de Steiner 1987, ofreciendo un catálogo de las reescrituras que se han realizado en España e Iberoamérica del mito de Antígona. Se completa, por tanto, el catálogo propuesto por Steiner, que remite a reescrituras francesas, alemanas, inglesas e italianas. 
vista terminológico ${ }^{2}$, esta investigación propone intentar descifrar las conexiones existentes entre la tragedia griega y su reescritura ${ }^{3}$.

De esta forma, la conexión atemporal que se establece entre una y otra, siendo la Antígona de Sófocles la que actúa como "hipotexto"4 de Antígona frente a los jueces, origina un vínculo literario no exento de complejidad. Al margen de las precisiones que pudieran establecerse acerca de los aspectos que afectan al proceso de creación de ambas obras así como de los matices que pudieran realizarse de forma general acerca de las conexiones textuales, este trabajo analiza la relevancia de los conceptos anomia (ausencia de ley) y dike (justicia) en el desarrollo dramático. Dichos conceptos, los cuales poseen relevancia meridiana en la esfera cívica del pensamiento griego, emergen como resorte fundamental para la acción de ambas obras y, por tanto, se convierten en elementos determinantes, desde un punto de vista cultural y social, en el proceso de reescritura llevado a cabo por Andrés Pociña.

\section{El término dike (JUSTICIA): Antígona}

El concepto dike constituye, casi en su totalidad, el resorte de la acción de nuestra osada protagonista femenina, Antígona, que desempeña el papel principal en ambas obras. Tal y como se puede deducir a priori, la profundidad conferida a este personaje en lo que a pensamiento y hechos se refiere posee una complejidad inherente a la esencia del conflicto trágico. Dentro de dicha complejidad, su oposición a los dictámenes del regente viene dada por el sentido de justicia, dike, que la Antígona de Sófocles aplica y que permite a Andrés Pociña extraer toda la rentabilidad del texto dramático sofocleo. Un análisis más preciso en lo que a su funcionamiento en la literatura griega se refiere permitirá arrojar luz sobre su importancia en el desarrollo de ambas tragedias.

En primer lugar, el concepto dike, susceptible de personificación ya en textos clásicos, posee connotaciones primigenias asociadas al sentido de respeto y consideración hacia los miembros de una comunidad ${ }^{5}$. Dike, por tanto, tomado como

${ }^{2}$ Dada la amplitud con la que la propia Julia Kristeva 1978 define el concepto de intertextualidad, aplicado para explicar relaciones textuales muy amplias, se empleará, a lo largo de este trabajo, el concepto "reescritura".

${ }^{3}$ No debe obviarse, como valor añadido, la importancia del vigor que poseen las reescrituras de la tragedia clásica, las cuales, a modo de reflexión, siguen siendo un resorte fundamental para la literatura actual. Así, el propio hecho de la reescritura demuestra que la universalidad inherente a la tragedia griega por naturaleza es garante de su pervivencia a través del tiempo.

${ }_{4}^{4}$ Término acuñado por el teórico literario Genette 1989: 14-15 para referirse al texto primario sobre el cual opera un proceso de transformación que da origen a otro texto distinto, denominado "hipertexto".

5 Así, si bien en un primer momento el concepto se encuentra relacionado con el proceder normal de la naturaleza, a partir de la época homérica emerge su relación con los procedimientos jurídicos que garanten los derechos legales ( $\mathrm{L} \& \mathrm{~S}$ s. v.). 
principio rector de la humanidad, sobrepasa los límites de los convencionalismos revelando matices más amplios y complejos, los cuales están en conexión con los deberes humanos, familiares y religiosos del ser humano.

Así, profundizar en la dimensión semántica y, fundamentalmente, en su envergadura cultural implica establecer matizaciones en su ámbito de aplicación. En este sentido, resulta indudable su conexión con aidos ${ }^{6}$, el pudor que inhibe el carácter en relación con nosotros mismos y con los demás. Los conceptos dike y aidos denotan, por tanto, desde sus primeras apariciones en los textos literarios, una importancia sustancial en las relaciones que el ser humano - sujeto que siente y padece - experimenta en su contacto con la sociedad. Se convierten, así, en términos fundamentales en la vida moral y social griega. Dan buena cuenta de ello textos de Hesíodo, Trabajos y Días 197-201 y de Platón, Protágoras 322 $\mathrm{c}-\mathrm{d}^{7}$, fuentes fundamentales para el funcionamiento de ambos términos en la moral tradicional griega:

Hes. Op. 197-201:

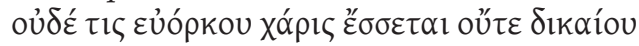

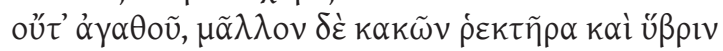

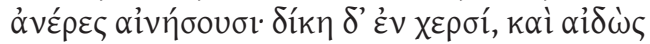

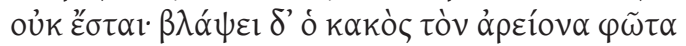

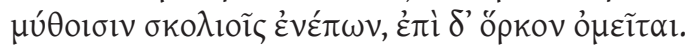

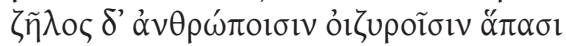

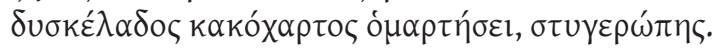

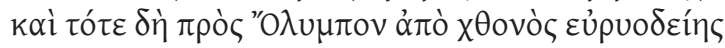

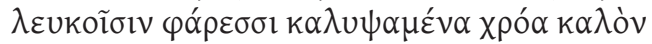

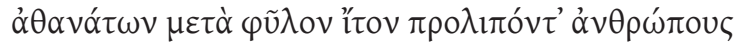

${ }^{6}$ Para una mayor profundización en el significado y funcionamiento del concepto aidos se remite al estudio monográfico de Cairns 1993.

${ }^{7} \mathrm{La}$ obra platónica confiere una muestra interesante acerca del tratamiento de los avances humanos, cuyo origen es tratado en el texto expuesto. Se entiende, pues, que los progresos asociados a la humanidad han de remitirse a un estadio primigenio en el cual la distribución de aidos y dike constituye la base para el desarrollo del ser humano en lo que a convivencia social se refiere. Véase, de forma sinóptica, el resumen del argumento mitológico: 320c (Apelación a Sócrates a fin de que demuestre que la virtud puede enseñarse)/320d (Génesis: creación, por parte de los dioses, de los mortales)/320e-321b (Epimeteo distribuye cualidades a los animales)/ 321c-321e (Prometeo roba la sabiduría y el fuego a Hefesto y Afrodita a fin de obtener la salvación del ser humano)/ 322a-322d (Reconocimiento de los hombres hacia los dioses/ Carencia del arte de la política/ Zeus envía a Hermes para otorgarles aidos y dike). Precisamente, en lo que al contenido de este relato se refiere, Adam y Adam (2001: 114 ss.) proponen que el mito relatado por Protágoras - relativo a los orígenes humanos y su especialización en el ámbito de la política,

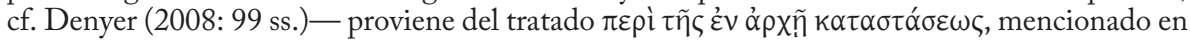
Diógenes Laercio 9. 55. De la misma manera, destacan que si no fue originalmente escrito por Protágoras sí está modelado siguiendo cuidadosamente su estilo de escritura (cf. la imitación del estilo de Agatón en su discurso del Simposio 194d ss. y el de Pródico en el pasaje posterior de 337a ss. en el mismo diálogo). Adam y Adam (2001: 114 ss.). 


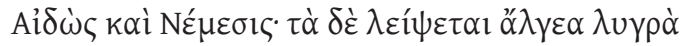

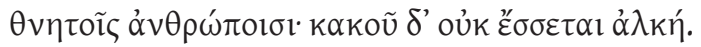

Ningún reconocimiento habrá para el que cumpla su palabra ni para el justo ni para el honrado, sino que tendrán en más consideración al malhechor y al hombre violento. La justicia estará en la fuerza de las manos y no existirá pudor; el malvado tratará de perjudicar al varón más virtuoso con retorcidos discursos y además se valdrá del juramento. La envidia murmuradora, gustosa del mal y repugnante, acompañará a todos los hombres miserables. Es entonces cuando Aidốs y Némesis, cubierto su cuerpo con blancos mantos, irán desde la tierra de anchos caminos hasta el Olimpo para vivir entre la tribu de los Inmortales, abandonando a los hombres; a los hombres mortales sólo les quedarán amargos sufrimientos y ya no existirá remedio para el mal ${ }^{8}$.

P1. Prt. 322c-d

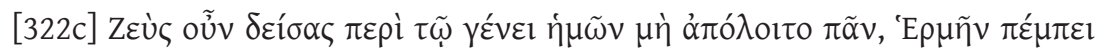

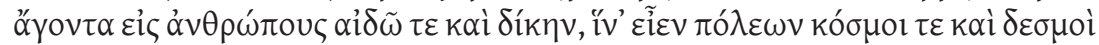

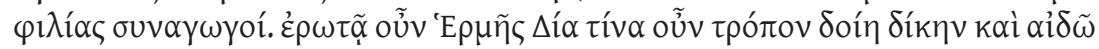

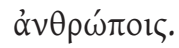

Así que, Zeus, temiendo por nuestro linaje que pereciera por completo, envía a Hermes con el respeto y la justicia para los hombres, para que sirvieran como principios rectores de las ciudades, y como lazos vinculantes de la amistad. Pues bien, pregunta Hermes a Zeus cómo debía entregar la justicia y el respeto a los hombres.

En los pasajes mencionados de Hesíodo y Platón ${ }^{10}$ dike y aidos se muestran como elementos fundamentales que son entregados a los hombres a fin de hacer factible la convivencia social y la destreza personal que se requiere para tal fin —de hecho, el pasaje platónico forma parte del mito de creación que Protágoras relata- Se trata, por tanto, de conceptos que rigen la vida humana en su desarrollo cívico y en su conducta individual, de tal forma que la ausencia de dike y aidos imposibilitaría un adecuado progreso social, que aúna lo individual y

${ }^{8}$ La traducción del texto de Hesíodo pertenece a Pérez y Martínez 1978.

${ }^{9}$ La traducción del texto de Protágoras pertenece a Serrano y Díaz de Cerio 2005.

${ }^{10}$ En ambos textos - la similitud de pensamiento debe buscarse en una posible influencia del texto hesiódico en el platónico- la proximidad subyacente entre los términos aidos y dike permite apuntalar que su coordinación resulta un principio rector de la conducta cívica, habiendo de entenderse esta, en su máxima expresión, como resultado del comedimiento y la equidad moral. De la esfera semántica de los términos mencionados pueden extraerse mayores precisiones. Así, debe notarse la especial importancia de aidos en sus dos dimensiones, a saber, social y personal, por lo que también se puede deducir que el ámbito de actuación de dike debe entenderse dentro de esta bidimensionalidad. 
lo colectivo. En el caso del texto platónico el hecho de que dike esté coordinado con aidos demuestra su importancia como "norma social" fundamental para la convivencia.

En el célebre mito de Protágoras son dos los elementos que la propia divinidad ha estimado oportunos para distribuir, en calidad de bienes inmateriales, a los seres humanos: dike y aidos. El vínculo de ambos conceptos con el propio origen de la convivencia social se hace evidente en el texto de Platón, debido a que dicha convivencia lleva implícito, per se, el hecho de que cada uno de sus miembros participe de cualidades como la justicia y el recato o comedimiento en lo que a su ámbito de aplicación comunitaria se refiere. Dike y aidos se alzan, pues, como cualidades que han llevado al ser humano de su estado primigenio a la excelencia cívica, materializada en el emerger de lo colectivo. Por otro lado, el texto hesiódico, si bien en un primer momento también coordina los conceptos dike y aidos (lo cual debe verse como una posible influencia en el texto platónico), también pone al mismo nivel la personificación de Aidos y Nemesis, la retribución, revelando una perspectiva de carácter más personal que denota un sentimiento íntimo claramente asociado con la censura e indignación: Nemesis. A través de esta reflexión, presente en el texto épico, se entiende que la justicia, dike, se encuentra conformada por principios fundamentales, aidos y nemesis, por lo que su aplicación debe verse en la ética individual la cual, por otro lado, resulta primordial para el entendimiento social.

De esta forma, las conexiones intelectuales y literarias que pueden deducirse del sentido de justicia que conforman la personalidad de Antígona, permiten establecer un aporte que no resulta trivial: estamos ante un personaje que no solo recoge las ideas patentes en la tradición trágica sino que también presenta una nueva dimensión de estas, las cuales también resultan objeto de reflexión en diálógos de Platón. Así, Antígona, evocando el sentido primigenio de dike, término ya asociado a aidos en la literatura hesiódica, como uno de los núcleos temáticos, adquiere, a través de sus palabras, un papel similar a Sócrates en el Protágoras de Platón; para ambos, la tradición y la experiencia resultan un eslabón fundamental para la comprensión cívica entre los miembros de una comunidad.

Así pues, de la propia historia literaria del término y de su relación con aidos se entiende buena parte del sentido de justicia que Antígona aplica en ambas obras, dando por supuesto, en relación con lo que se ha expuesto, que dike resulta un fundamento de carácter divino, impuesto por los dioses y no por los hombres y que conlleva un sentimiento de respeto hacia la propia familia $y$ la religión, relevantes tanto en la esfera personal como social. A la luz de estas consideraciones puede entenderse el auténtico sentido de justicia propuesto por nuestra protagonista, que impone su sentido de respeto a la familia como norma personal; así lo muestra en los versos 45-46 al responder a su hermana Ismene: "Sí, porque se trata de mi hermano, y también del tuyo aunque no quieras. Pues, 
al enterrarlo, no resultaré convicta de haber cometido una traición"11; similar a sus palabras en los versos 72-77: "Es un honor para mí morir cumpliendo este deber. Querida por él, en su compañía yaceré, en compañía de quien yo quiero, tras haber perpetrado santas acciones, porque es más largo el tiempo durante el que debo agradar a los de abajo que el tiempo durante el que debo agradar a los de aquí arriba, pues allí yaceré por siempre. Pero tú, si es tu gusto, continúa apreciando lo que los dioses aprecian”. Porque, al fin y al cabo, Antígona sabe que sus palabras y acciones son consecuentes con el sentido de la auténtica justicia, la que ella misma entiende como entidad de origen divino, en los versos 450-452 en los que no debe obviarse la personificación del concepto dike: "Es que no fue Zeus en absoluto quien dio esta orden, ni tampoco la justicia aquella que es convecina de los dioses del mundo subterráneo. No, no fijaron ellos entre los hombres estas leyes".

La versión contemporánea de Andrés Pociña recoge, precisamente, los fundamentos ya descritos, que confieren a Antígona una dimensión profundamente humana, a la par que trágica por las consecuencias que su concepción de la justicia implica para ella. Así, en Antígona frente a los jueces afirma que (113) "hay cosas que no están escritas en las leyes ni contempladas en las costumbres, pero se encuentran inscritas en el interior de nuestros corazones"; en esta misma línea (111): "Creonte, ni como tío, ni como cabeza de familia, ni menos todavía como único responsable del gobierno de Tebas, tenía derecho a impedirme cumplir con un deber familiar, humano y religioso fundamental". Antígona materializa así su derecho, un derecho que vulnera las leyes impuestas por Creonte pero que es lícito si se tiene en cuenta el profundo sentido de respeto familiar que Antígona atribuye al sentido de justicia. Afirma así (102): "yo enterré a Polinices porque era una persona, porque estaba muerto, porque era mi hermano. Ahí está la verdad completa, y eso no hay ley, ni divina ni humana, que pueda castigarlo". De esta forma, el valor sagrado e inviolable de la justicia impide, tal y como Antígona afirma, que la justicia pueda ser ambigua (119): "la justicia no parece ni deja de parecer: es justicia, o no lo es. Puede parecer que tiene más de un aspecto, pero auténtico solo puede ser uno".

\section{El término anomia (ausencia de leyes): Creonte}

El contrapunto a las consideraciones que Antígona ofrece acerca de la justicia, dike, resulta ser Creonte, cuyo sentido de autoridad y respeto a las leyes resulta profuso en detalles. Precisamente, a este respecto, es necesario sacar a colación el concepto anomia, la ausencia o carencia de leyes comunitarias. Dentro de la sociedad griega, la preservación de las leyes y la protección de lo comunitario

${ }^{11}$ Las traducciones del texto de la Antígona de Sófocles presentes en este trabajo pertenecen a Alsina, Vara y López 2004. 
emergen como garantes frente a los poderes subversivos que conducen a un estado de anomia (ausencia de leyes o negación de estas), totalmente contrario a la vida en comunidad. Creonte resulta, a todos los efectos, en ambas obras, la máxima autoridad en la ciudad de Tebas y, como tal, se aferra al miedo colectivo a la anomia para promulgar indiscriminadamente leyes y decretos que camuflan sus ansias de poder y despotismo bajo la faz de los intereses comunitarios.

A lo largo de la literatura griega, fundamentalmente dramática, el miedo a la ausencia de leyes o la negación de estas pone de manifiesto la teoría derrotista de la humanidad, evocándose el estado asocial que se deriva de ciertas conductas humanas. Así deben entenderse los versos 1089-1097 de la tragedia Ifigenia en Aulide, de Eurípides.

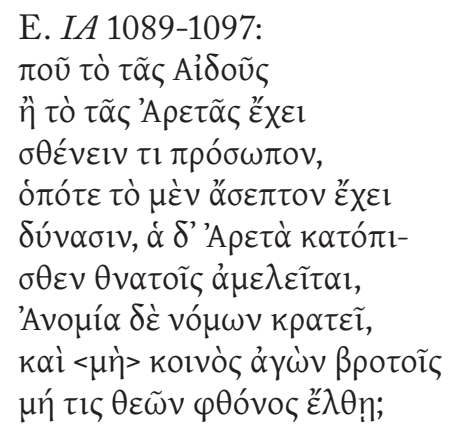

¿En dónde le resta ya algún poder a la faz de Pudor o de Virtud, toda vez que la impiedad posee ahora el mando, la Virtud, arrinconada ya no interesa a los mortales, la ilegalidad gobierna las leyes, y no hay un común empeño entre los mortales para que no caiga sobre ellos la envidia de los dioses? ${ }^{12}$

En ese fragmento coral, nuevamente el término aidos, cuya importancia ha quedado constatada en su asociación con dike, que figura en una estructura interrogativa coordinado con arete, expresa una idea de vergüenza restrictiva que se encuentra intrínsecamente vinculada a la noción de excelencia (arete). La personificación de ambos conceptos abstractos constituye una estrategia para dotar de relevancia a estas entidades presentadas como fuerzas motrices de la conducta social en un coral que colige un mensaje central de la tragedia. Tanto las personificaciones de los vv. 1089-1090 como la pregunta retórica que indaga sobre la ubicación de las virtudes evoca el pasaje hesiódico de Op. 197-201 en la descripción de un mundo en el que el orden común se halla subvertido. El retrato de la subversión adopta una recurrente imagen centrada en el poder (sthenei, dunasin, kratei) ejercido por fuerzas anómalas. Así, en la primera sección del

\footnotetext{
${ }^{12}$ La traducción del texto de Eurípides pertenece a Alsina, Vara y López 2004.
} 
estásimo se expresa la desolación ante la ineficacia de las virtudes aidos y arete; en la segunda parte, se completa la explicación en sentido contrario describiendo el predominio efectivo de las antivirtudes asepton (la ausencia de sebas) y anomia (la ausencia de nomos), que no se contemplan como mera ausencia sino como entidades negativas agentivas. Esta correlación de contarios que se forja entre aidos y arete por una parte y asepton y anomia por otra resulta crucial para entender el ejercicio de autoridad llevado a cabo por Creonte en ambas obras.

La introducción del concepto anomia personificado conecta, a su vez, el texto euripideo con obras del ámbito jurídico, como la oratoria forense de Antifonte ${ }^{13}$, y reflexiones teóricas sobre el estado ciudadano como la República de Platón ${ }^{14}$. Los textos refuerzan el valor técnico de anomia en su acepción de la legalidad y el orden ciudadano que garantiza la estabilidad del propio estado; por tanto, si en el texto dramático anomía funciona como un término opuesto a aidos, podría plantearse postular un matiz semántico acorde como "(la actuación de autorrestricción dictada por la) conciencia cívica".

Resulta evidente, pues, que el estado de anomia viene a ser la antítesis de polis, de tal forma que, el correcto respeto a las leyes promueve el auténtico avance de la humanidad. Precisamente, Sófocles (S. Ant. 334-383) elabora una oda coral dedicada exclusivamente a los avances del ser humano, que ya tiene sus precedentes en Esquilo ${ }^{15}$.

En conexión con la idea expuesta, los versos sofocleos dan cuenta de un avance de la humanidad que el coro contrapone a la actitud de Antígona precisamente

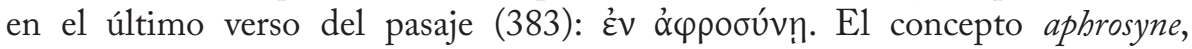
fundamental para definir el comportamiento de la protagonista, tildado de poca sensatez, quebranta bruscamente la armonía presente en la exposición previa, la cual se articula en torno a los avances que el ser humano se ha ido granjeando a lo largo del tiempo. Se evidencia, por tanto, una dicotomía entre el progreso que ha experimentado el hombre y la carencia de sensatez en su conducta cívica. En este caso, una conducta definida mediante el concepto aphrosyne constituye la base de la anomia según la interpretación de Creonte.

Teniendo ya el ser humano la facultad de relacionarse en sociedad, tal y como se expone en la oda coral de Antígona de Sófocles, se imponen la moderación y la sensatez como cualidades que ayudan a preservar el orden cívico, constituyendo la carencia de estas cualidades un estado de anomia. El personaje, en consecuencia, a ojos del coro, encarna la aphrosyne, la cual, en

${ }^{13}$ Véase, a este respecto, Antiph. 4.7. Asimismo, cabe destacar la preferencia de este autor por la creación y el uso de nombres abstractos, tales como anomia. Así lo expresa Gagarin (1997: 26): "The court speeches generally prefer abstract nouns in - $-1 \varsigma$, the Tetralogies nouns in $-i \alpha$ or $-\varepsilon \imath \alpha$, but the significance of this difference is unclear".

${ }^{14}$ Así en Pl. R. 6.496 c-d.

${ }^{15}$ Cf. A. PV 436-506. 
sus efectos prácticos inmediatos conduce a la anomia, la ausencia de leyes en la comunidad. Este hecho es, precisamente, el que parece conferir a Creonte la excusa necesaria para legislar de forma autoritaria y despótica, pues considera que los pensamientos de la protagonista sobrepasan los límites comúnmente establecidos para los mortales, recayendo, por tanto, en hybris, la insolencia que eleva al ser humano por encima de los dioses. Las reflexiones intelectuales de Antígona, alejadas de la órbita de lo común, suponen un daño para la polis, poniendo en riesgo a la colectividad ante la cual Creonte debería mostrarse, como regente, de forma contraria, siendo el máximo garante de las tradiciones y, consecuentemente, de la vida en sociedad.

Ciertos pasajes, extraídos de ambas obras, dan buena cuenta de la información expuesta. Así, Creonte, en la Antígona de Sófocles muestra su convicción de que el ser humano únicamente puede ser debidamente conocido cuando se aclara su relación hacia las leyes, pudiendo observarse que, para Creonte, la esfera cívica, en su aspecto legislativo, es la única relevante para explicar las conductas del individuo, entendido únicamente de forma unidimensional. Así en los versos 175-177: "No hay medio de conocer el espíritu, pensamientos y puntos de vista de hombre alguno antes de que se aclare en contacto con el mando y las leyes"; o las palabras proferidas en su célebre discurso en de defensa de las leyes y de la autoridad en el que llega a afirmar que: "quien es hombre de bien en lo particular se verá que también en lo público es justo, pero el que con sus transgresiones fuerza las leyes o se le ocurre señalar a las autoridades lo que tienen que hacer, no es cosa de que ese individuo consiga mi aprobación" (660-663).

Resulta, pues, evidente, que la personalidad dramática del regente Creonte únicamente puede ser entendida a la luz de los convencionalismos y de las leyes que conforman la comunidad, todo ello, a priori, en respuesta a la anomia o carencia de leyes que harían de la polis un lugar no apto para la convivencia. Este personaje, de menor relevancia en Antígona frente a los jueces, se muestra en la obra de Andrés Pociña como un personaje lineal que presenta una tendencia obsesiva en lo que a la necesidad de legislar se refiere. Así, cuando es increpado por el pueblo cuarto en relación a la libertad de la que goza Antígona en sus intervenciones su respuesta es (110): "No debería ser así. Tendremos que ocuparnos de eso más adelante”. Asimismo, en Antigona frente a los jueces también se recoge buena parte de su carácter autoritario y déspota, tal y como se desprende de sus palabras a la jueza cuando interroga a Antígona acerca de su padre Edipo (114): “ ¡Al asunto, jueza! No hemos venido aquí para juzgar al rey Edipo”. Por último, y debido a que sus intervenciones en esta obra no resultan extensas, es Antígona la que finalmente describe la diferencia transcendental entre ambos al afirmar que (121): "Entonces no hay conciliación posible, rey Creonte. Antígona actúa por deberes y por principios, tú por mantener una imagen determinada. Antígona actúa por amor a su hermano, tú por conservar el poder. Antígona jamás pactará nada contigo, Creonte”. 


\section{Conclusiones}

Se infiere, en conexión con lo expuesto, que Creonte confunde las leyes con el ejercicio de la autoridad y, a la hora de aplicar los principios legales obvia totalmente la dimensión humana que, por otro lado, tan necesaria resulta para su correcta aplicación. Así, las palabras puestas en boca de Creonte permiten deducir buena parte de su caracterización dramática, a través de la cual se observa un personaje que entiende al ser humano en función de su respeto a las leyes y a la autoridad.

El concepto de justicia, dike, tal y como es entendido por Antígona, se encuentra relacionado con el sentido de respeto y pudor (aidos), también de origen divino, que hace factible la convivencia cívica, proponiéndose así una doble dimensión: la justicia proclamada en las leyes debe ayudar a mantener las libertades y derechos del individuo pero también debe respetar la complejidad de la dimensión humana, que en ocasiones sobrepasa el ámbito meramente legislativo.

Por otro lado, se observa que el término anomia (contrario a aidos y arete) en su aplicación a la conducta de Creonte pretende contrarrestar la insensatez presente en las conductas individuales. Sin embargo, Creonte se aferra a esta idea para sobrepasar su propia función como gobernante, recayendo en bybris a través de su tiranía.

Finalmente, como es característica afín a la tragedia, el elevado rendimiento dramático que Antígona presenta en ambas obras está relacionado con el sentido de justicia. Dike para Antígona no resulta una virtud que pueda ser entendida únicamente en relación a las leyes impuestas por los convencionalismos, sino un valor que sobrepasa lo meramente formal y que indaga en la auténtica naturaleza del ser humano, cuya complejidad no siempre puede ser entendida desde un punto de vista social. 


\section{Bibliografía}

Alsina J., Vara J., López Férez J. A. (2004), Obras completas. Esquilo, Sófocles y Eurípides. Cátedra: Madrid.

Adam, J., Adam, A. M. (2001), Plato. Protagoras. London: Bristol Classical Press.

Cairns, D. (1993) Aidos: the psychology and ethics of honour and shame in ancient Greek literature. Oxford: Clarendon Press.

Denyer, N. (2008), Plato. Protagoras. Cambridge: Cambridge University Press.

Gagarin, M. (1997), Antiphon. The Speeches. Cambridge: Cambridge University Press.

Genette, G., (1989) Palimpsestos. La literatura en segundo grado. Trad. Fernández, C. Madrid: Taurus.

Kristeva, J. (1967), “Le mot, le dialogue et le roman”, Semiótica 1: 187-225.

Pérez A., Martínez A. (1978), Hesiodo. Obras y fragmentos. Madrid: Gredos.

Pociña, A. (2015), Medea en Camariñas. Atardecer en Mitilene. Antígona frente a los jueces. Granada: Esdrújula Ediciones.

Pociña, A., López, A. (2010), "La eterna pervivencia de Antígona”, Florentia Iliberritana 21: 345-370.

Serrano, R., Díaz de Cerio, M. (2005), Platón. Protágoras. Madrid: CSIC.

Steiner, G. (1987), Antígonas. Una poética y una filosofía de la lectura. Trad. Bixio, A. L. Barcelona: Gedisa. 